\title{
Individual and contextual determinants of perceived peer smoking prevalence among adolescents in six European cities
}

\author{
Mirte A.G. Kuipers a,*, Pierre-Olivier Robert ${ }^{b}$, Matthias Richter ${ }^{c}$, Katharina Rathmann ${ }^{c}$, Arja H. Rimpelä d,e,f, \\ Julian Perelman ${ }^{\mathrm{g}}$, Bruno Federico ${ }^{\mathrm{h}}$, Vincent Lorant ${ }^{\mathrm{b}}$, Anton E. Kunst ${ }^{\mathrm{a}}$ \\ a Department of Public Health, Academic Medical Center, University of Amsterdam, Amsterdam, The Netherlands \\ b Institute of Health and Society, Université Catholique de Louvain, Brussels, Belgium \\ ' Institute of Medical Sociology (IMS), Medical Faculty, Martin Luther University Halle-Wittenberg, Halle (Saale), Germany \\ d School of Health Sciences, University of Tampere, Tampere, Finland \\ e Department of Adolescent Psychiatry, Pitkäniemi Hospital, Nokia, Tampere University Hospital, Tampere, Finland \\ ${ }^{\mathrm{f}}$ PERLA Tampere Centre for Childhood, Youth and Family Research, Finland \\ g National School of Public Health, University of Lisbon, Lisbon, Portugal \\ h Department of Human Sciences, Society and Health, University of Cassino and Southern Lazio, Cassino, Italy
}

\section{A R T I C L E I N F O}

\section{Article history:}

Received 16 July 2015

Received in revised form 13 April 2016

Accepted 16 April 2016

Available online 19 April 2016

\section{Keywords:}

Smoking

Perceived smoking prevalence

Descriptive social norm

Adolescents

Schools

Educational leve

Socioeconomic position

\section{A B S T R A C T}

Background. Young people perceiving a high peer smoking prevalence are more likely to initiate smoking. It is unclear which factors contribute to perceived peer smoking prevalence and if these factors vary according to education. This study aimed to assess the determinants of perceived smoking prevalence and assessed its variation at school and country-level.

Methods. Data of 10,283 14-17-year-old students in 50 secondary schools in six European cities were derived from the 2013 SILNE survey. The outcome was the perceived smoking prevalence score among peers at school (0-10 scale, 10 represented $100 \%$ smoking prevalence). Multilevel linear regression models estimated the associations of factors with perceived prevalence score and variance at school and country-levels. Analyses were also stratified by academic achievement of the adolescent and parental education.

Results. Determinants of a higher perceived prevalence score were female sex, ever smoking, having friends who smoke, low academic achievement, low parental educational level, and higher actual prevalence of smoking in the school. The perceived prevalence score was not associated with school policies or with the availability of cigarettes near the school. Determinants were very similar across levels of academic achievement and parental education. Perceived prevalence scores substantially varied between schools and countries: $10 \%$ and $11 \%$ of total variance was related to schools and countries respectively.

Conclusion. Across educational levels, perceptions of peer smoking are strongly determined by both individual characteristics and school and national contexts. Future studies should assess why perceived smoking prevalence varies between schools and countries and identify modifiable factors.

(C) 2016 Elsevier Inc. All rights reserved.

\section{Introduction}

Adolescent smoking rates in Europe have declined over the recent years, but not all European countries show a downward trend (de Looze et al., 2013; Hibell et al., 2012). The majority of smokers initiated smoking before 18 years of age, and 39\% smoked their first cigarette before they were 16 (Lifestyle statistics team, 2014). Earlier smoking onset leads to more severe nicotine dependence and earlier manifestation of chronic smoking-related illness (US Department of Health Human Services, 2012, 2014). Prevention of smoking initiation in adolescence

\footnotetext{
* Corresponding author at: Department of Public Health, Academic Medical Center, University of Amsterdam, P.O. Box 22660, 1100 DD Amsterdam, The Netherlands.

E-mail address: m.a.kuipers@amc.uva.nl (M.A.G. Kuipers).
}

is essential to reduce the smoking-related disease burden in Europe in the future.

Initiation of smoking in adolescents is typically influenced by the social context, including family, peers and schools (Alexander et al., 2001; Hoffman et al., 2006; Kobus, 2003). According to social learning theory, behaviours are learned through the observation of others and the subsequent modelling of behaviour (Bandura and McClelland, 1977). Social learning theory is highly applicable to smoking uptake in adolescents (Hoffman et al., 2006; Kobus, 2003) and the school is one of the primary contexts in which smoking uptake occurs (Kobus, 2003).

Previous research indicates that smoking uptake is more determined by the perception of the prevalence of peer smoking rather than the actual smoking prevalence rates (Ellickson et al., 2003). Higher perceived smoking prevalence is a strong risk factor of smoking (Edwards et al., 
2008; Ellickson et al., 2003; Lai et al., 2004; Nichols et al., 2006; Otten et al., 2009; Thrul et al., 2013; Wang et al., 2011; Wiium et al., 2006; Zaleski and Aloise-Young, 2013; Zehe et al., 2013), with some studies estimating an $80 \%$ higher likelihood of having initiated smoking after two years in those who overestimated smoking prevalence at baseline (Edwards et al., 2008; Wang et al., 2011). Depending on the setting and the definition of overestimation, previous studies found that 25 to $90 \%$ of adolescents overestimated the smoking prevalence (Conley Thomson et al., 2005; Edwards et al., 2008; Lai et al., 2004; Otten et al., 2009; Wang et al., 2011) and that perceived smoking prevalence was more than twice as high as the actual smoking prevalence (Elsey et al., 2015; Pedersen et al., 2013; Unger and Rohrbach, 2002). In order to prevent smoking in young people, it is important to influence smoking prevalence perceptions towards lower, more realistic levels.

Within the same school, the perceived smoking prevalence can vary to a large extent between groups of students (Brown et al., 2010; Conley Thomson et al., 2005; Javier et al., 2013; Pedersen et al., 2013; Unger and Rohrbach, 2002). For example, perceived smoking prevalence rates have been found to be higher in adolescents of lower socioeconomic position (SEP) than in their high SEP counterparts (Doku et al., 2010; Pförtner et al., 2014; Richter and Leppin, 2007), in females than in males (Javier et al., 2013; Pedersen et al., 2013; Unger and Rohrbach, 2002) and in adolescents who have more friends who are smokers (Conley Thomson et al., 2005; Unger and Rohrbach, 2002). However, subgroup variations have hitherto only been studied in the USA, and not in the European context.

Perceptions of the school-level smoking prevalence have previously been found to strongly vary between schools, indicating that the school context may play an important role (Wiium et al., 2006). Schools differ in their physical environment which may be related to the availability of cigarettes around the school. The extent to which smoking is actively controlled with smoking policies also varies between schools (Galanti et al., 2013). However, to our knowledge, no study to date assessed which school characteristics, independent of the characteristics of individual students, may influence the perception of peer smoking prevalence.

Evidence on individual-level and school-level determinants of perceived smoking prevalence may inform policies or interventions aimed to alter false perceptions among adolescents. Also, since perceived smoking prevalence is an aspect of descriptive social norm (Lapinski and Rimal, 2005), altering false perceptions might help denormalise smoking. This would be particularly helpful within the group of lower SEP adolescents, among whom smoking rates are higher than among those of high SEP (de Looze et al., 2013). Unfortunately there is little evidence that specific policies to prevent smoking are more effective in adolescents with low SEP than among those with high SEP (Brown et al., 2015; Hiscock et al., 2012).

The aims of this study were to assess the determinants of the perceived smoking prevalence and to assess its variation at the school and country-level. We additionally explored if determinants differed between adolescents of low SEP and those with high SEP. By analysing information of six cities in Europe, we aimed to derive conclusions that may be applicable to the wider European context.

\section{Methods}

\subsection{Study population}

Data were derived from the SILNE (Smoking Inequalities: Learning from Natural Experiments) secondary school survey, which was conducted between January and November 2013. Secondary schools were invited in six European cities: Namur (Belgium), Hannover (Germany), Tampere (Finland), Latina (Italy), Amersfoort (the Netherlands) and Coimbra (Portugal). Ethical approval was obtained in all countries where approval was required. Questionnaires were self-administered and were completed in classrooms, under the surveillance of a research fellow and/or a teacher. More details on the survey were published elsewhere (Lorant et al., 2015).

In the 50 participating schools 13,870 students were invited of whom 11,015 (79.4\%) completed the student questionnaire. For this analysis we excluded students aged $12,13,18$ or 19 years $(\mathrm{N}=424)$, those with missing information on age $(\mathrm{N}=81)$, and students with missing information on perceived smoking prevalence $(\mathrm{N}=227)$. The total study population consisted of 10,283 individuals. Furthermore, individuals with missing values on academic achievement $(\mathrm{N}=223)$ and parental educational level $(\mathrm{N}=1246)$ were excluded in the stratified analysis.

School-level information was derived from self-administered questionnaires completed by 276 individuals of the school staff.

\section{Measures}

\subsection{Outcome}

The perceived smoking prevalence score was measured with the following question: 'In your opinion, what percentage of people of your age in your school smoke cigarettes?'. Answers were provided on a discrete scale of 0 to 10 , with 0 defined as perceiving $0 \%$ smokers in the school and 10 defined as perceiving 100\% smokers.

\subsection{Individual determinants}

Demographics included were age (in years), gender (male vs. female), and foreign background (foreign background vs. native background). Respondents with one or two parents born in a country other than the country of residence were defined as having a foreign background. We used the country of birth of the parents to determine students' foreign background, because patterns of upbringing may largely vary according to the foreign background of the parents (Yaman et al., 2010).

Academic achievement was measured on a country specific scale using the grading system of each country and was categorised into 'insufficient', 'low', 'average', 'good', or 'high'. In the analysis 'insufficient' and 'low' were combined due to low numbers in the 'insufficient' category. In the stratified analysis academic achievement was dichotomised into low (insufficient, low or average) and high (good or high). Educational level of parents was measured using country-specific categories and was standardised into 'low', 'middle', and 'high'. In most countries 'low' corresponded to primary school and/or a lower level of secondary school, 'middle' corresponded to completed secondary school and/or lower level college, and 'high' corresponded to college or university degree. For each respondent the information of the parent with the highest educational level was used. Parental educational level was dichotomised for the stratified analysis, into 'low' (low or middle educational level) and 'high' (high educational level). Students who did not report at least one parent's educational level were excluded from the stratified analysis.

The smoking behaviour of the student was measured in six categories: 'never-smoker', 'ever tried smoking once', 'experimenter' (have smoked once or twice during the past 30 days), 'regular smoker' (at least weekly, but not daily smoking), 'daily smoker', and 'ex-smoker' (did smoke, but not in the past 30 days).

Three variables captured the smoking environment. Smoking behaviour of best friends was measured in four categories: 'none of them smoke', 'some of them smoke', 'most of them smoke', and 'all of them smoke'. Smoking behaviour of (step)parents was divided into 'no smoking (step)parents', 'one smoking (step)parent', and 'two or more smoking (step)parents'. Smoking rules at home were measured in three categories: 'smoking is not permitted in the home', 'smoking is only permitted in certain areas', 'smoking is permitted everywhere in the home'. 


\subsection{Contextual determinants}

Actual smoking prevalence among students in the same school was measured as the aggregated percentage of weekly smokers in the school. The actual smoking prevalence was weighted by age to control for differences between schools in age distribution. The percentage was divided by ten (resulting in a $0-10$ scale), so that regression coefficients present the change in the perceived prevalence score with an increase of $10 \%$ smokers in the surveyed school-population.

School staff members were asked whether or not cigarettes were sold within $100 \mathrm{~m}$ of the school building. Response options were 'yes' or 'no'. If school staff was not unanimous, the most opted answer was selected. In schools where 'yes' and 'no' were answered evenly, the response of the (vice) principal was decisive. School smoking policy reported by the school staff was measured on a scale of 0 to 10 . The scale was based on 52 (sub-)questions from the staff questionnaire, including items on smoking bans, advertising bans, communicating policy to students, and sanctioning (see Supplement I for included items). These items have been used in previous research on school smoking policies (Kuipers et al., 2015a). All items had a value of 0 or 1 , and the sum score was divided by 5.2 to obtain a $0-10$ school smoking policy score for each school.

\section{Statistical analysis}

The perceived prevalence score was modelled using multilevel linear regression models with 3 levels; country, school, and individual. Model 0 was an intercept only model. The following six models were all controlled for the actual weekly smoking prevalence in the school. Models 1, 2 and 3 included variables related to peers and the school environment. Model 1 only included actual weekly smoking prevalence. Model 2 included the smoking behaviour of friends. Model 3 included the school-level variables cigarette availability within $100 \mathrm{~m}$ of the school, and school smoking policy. Models 4 and 5 included individual characteristics. In Model 4 the smoking behaviour of respondents and parents and the smoking rules at home were included. Model 5 included demographics age, gender, foreign background, and educational variables. Model 6 integrated all variables. Model 6 was repeated in strata of high and low academic achievement and parental educational level. We tested for interaction between each covariate and SEP (e.g. between actual smoking prevalence and academic achievement).

In each model, the intraclass correlation coefficient (ICC) for school and county level and the residual variance were reported. The ICC represents the variance at the corresponding level as a percentage of the total variance (Merlo et al., 2006). All analyses were conducted in $\mathrm{R}$ using the lme4 package.

\section{Results}

Table 1 presents the individual-level characteristics of the study population. Students had a mean age of 15 years; $47 \%$ were boys. The prevalence of low academic achievement and low parental educational level was relatively high in older students, in daily smokers, and in students with smoking parents and friends. The perceived prevalence score was relatively high in the same subgroups.

Table 2 describes the study population at the school-level. All schools weighted equally in this table. Perceived smoking was lowest in Amersfoort (the Netherlands) and Tampere (Finland) and relatively high in Latina (Italy) and Namur (Belgium). Cities with high perceived prevalence scores showed higher actual smoking rates. Most schools in Namur (85.7\%) reported that cigarettes were available within $100 \mathrm{~m}$ of the school building, compared to $37.5 \%$ of the schools in Amersfoort. School smoking policies were most developed in Tampere and Coimbra (Portugal) while policy scores were somewhat lower in Amersfoort and Latina.
Fig. 1 presents the actual school smoking prevalence plotted against the perceived smoking prevalence score. There is a clear linear association between perceived and actual smoking prevalence, with higher actual smoking rates being associated with higher perceived smoking scores $(r=0.73, p<0.001)$.

The fixed effects in Table 3 present the associations between covariates and the perceived prevalence score. Higher actual school smoking prevalence was associated with higher perceived prevalence scores (Model 1, $\beta=0.75,95 \% \mathrm{CI}=0.53 ; 0.99$ ). Students of whom most friends were smokers reported a 1.50 point higher perceived prevalence score $(95 \% \mathrm{CI}=1.39 ; 1.61)$ than students who did not have friends who smoked, and the actual smoking prevalence became a weaker determinant when smoking behaviour of friends was included (Model 2). The availability of cigarettes around the school was associated with a higher perceived prevalence score (Model 3), but this association disappeared when controlled for other covariates (Model 6). In all groups of smokers the perceived prevalence score was higher compared to never-smokers. For example daily smokers had a 0.94 points $(95 \% \mathrm{CI}=0.83 ; 1.06)$ higher score than never-smokers (Model 4). Having parents who smoke and living in a household where smoking is permitted was associated with higher perceived prevalence scores (Model 4). Perceived prevalence scores were lower in males than in females and increased with age (Model 5). Model 5 shows that perceived prevalence scores were significantly lower in students with high academic achievement $(\beta=-0.85$, $95 \% \mathrm{CI}=-1.00 ;-0.70)$ and in students with highly educated parents $(\beta=-0.28,95 \% \mathrm{CI}=-0.40 ;-0.16)$. Results are similar in Model 6, although smoking status of the student and parents were weaker determinants in Model 6 than in Model 4.

Table 3 also presents the random effects at the school and countrylevel. In Model 0, 20\% of the variance in perceived prevalence score was associated with the school-level and $26 \%$ with the country-level. The variance at the school and country-level was largely reduced by the actual smoking prevalence at schools (Model 1). Smoking behaviour of friends also largely reduced the variance, at both levels (Model 2). The availability of cigarettes around the school and the smoking policy of the school did not explain variance at any level (Model 3). Individual-level characteristics did not explain variation in the perceived prevalence score at school and country-level (Models 4 and 5). After control for all covariates combined (Model 6) respectively 10 and $11 \%$ of variance was associated with the school and country-level.

In Table 4 the full model (Model 6) is presented for subgroups of academic achievement and parental educational level. The $p$-values for interaction indicate the level of significance of interaction tests between academic achievement or parental educational level and the covariates presented in the table. The $p$-values were $>0.05$, implying that most determinants of perceived prevalence were very similar between high and low academic achievement and parental educational level. However, smoking behaviour of friends was a stronger predictor of perceived smoking in students with high than with low academic achievement. School-level variance was larger in students with low academic achievement and low parental educational level (around 12\%) than in their counterparts (around 8\%). Country-level variance was higher in students with high academic achievement and high parental educational level (22 and 19\%, respectively) than in low academic achievement and low parental educational level (8\%).

\section{Discussion}

\subsection{Key findings}

Determinants of higher perceived smoking prevalence scores were female sex, ever smoking, having friends who smoke, low academic achievement, low parental educational level, and higher actual prevalence of smoking in the school. The perceived prevalence score was not associated with school policies or with the availability of cigarettes in the school surroundings. Determinants were very similar for students 
Table 1

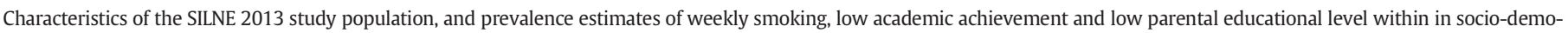
graphic groups.

\begin{tabular}{|c|c|c|c|c|c|}
\hline & \multirow{2}{*}{$\begin{array}{l}\text { \% in total study } \\
\text { sample }\end{array}$} & \multirow{2}{*}{$\begin{array}{l}\text { Mean perceived prevalence score } \\
\pm \text { SD }\end{array}$} & \multicolumn{3}{|c|}{ Prevalence estimates in subgroups } \\
\hline & & & $\begin{array}{l}\% \text { at least weekly } \\
\text { smokers }^{a}\end{array}$ & $\begin{array}{l}\text { \% low academic } \\
\text { achievement }^{b}\end{array}$ & $\begin{array}{l}\text { \% low parental educational } \\
\text { level }^{\mathrm{c}}\end{array}$ \\
\hline General population & & $5.14 \pm 2.43$ & 18.7 & 58.0 & 53.9 \\
\hline Age $($ mean $\pm S D)$ & $15.19 \pm 0.91$ & & & & \\
\hline 14 & 24.6 & $4.29 \pm 2.42$ & 10.0 & 51.6 & 49.1 \\
\hline 15 & 40.5 & $4.89 \pm 2.39$ & 15.6 & 55.2 & 52.3 \\
\hline 16 & 26.1 & $5.68 \pm 2.26$ & 25.1 & 67.7 & 56.5 \\
\hline 17 & 8.8 & $6.43 \pm 2.08$ & 38.2 & 76.5 & 65.9 \\
\hline Females & 52.6 & $5.43 \pm 2.37$ & 18.0 & 65.1 & 54.3 \\
\hline Males & 47.4 & $4.69 \pm 2.43$ & 19.5 & 54.0 & 53.4 \\
\hline Native background & 79.5 & $5.04 \pm 2.43$ & 18.9 & 58.5 & 54.1 \\
\hline foreign background & 20.5 & $5.25 \pm 2.41$ & 17.9 & 62.7 & 53.3 \\
\hline \multicolumn{6}{|l|}{ Academic achievement } \\
\hline Insufficient or low & 17.6 & $5.49 \pm 2.25$ & 30.7 & 100 & 63.6 \\
\hline Average & 40.8 & $5.10 \pm 2.43$ & 20.1 & 100 & 57.9 \\
\hline Good & 31.2 & $4.96 \pm 2.47$ & 12.6 & - & 48.6 \\
\hline High & 10.4 & $4.48 \pm 2.45$ & 6.7 & - & 36.1 \\
\hline \multicolumn{6}{|l|}{ Education parents } \\
\hline Low & 13.7 & $6.12 \pm 2.24$ & 22.0 & 68.3 & 100 \\
\hline Middle & 40.2 & $5.56 \pm 2.33$ & 21.6 & 62.9 & 100 \\
\hline High & 46.1 & $4.49 \pm 2.38$ & 15.4 & 50.7 & - \\
\hline \multicolumn{6}{|l|}{ Smoking rules at home } \\
\hline Nobody is allowed & 51.3 & $4.82 \pm 2.46$ & 14.7 & 55.6 & 47.8 \\
\hline Certain areas & 30.1 & $5.51 \pm 2.34$ & 24.2 & 63.3 & 63.0 \\
\hline Everywhere & 6.1 & $6.02 \pm 2.23$ & 31.7 & 67.6 & 69.5 \\
\hline \multicolumn{6}{|l|}{ Smoking respondent } \\
\hline Never-smoker & 50.9 & $4.43 \pm 2.38$ & - & 50.3 & 49.2 \\
\hline Tried smoking & 9.6 & $5.39 \pm 2.39$ & - & 59.9 & 55.7 \\
\hline Experimenter & 13.1 & $5.37 \pm 2.25$ & - & 68.5 & 52.0 \\
\hline Regular smoker & 4.3 & $5.70 \pm 2.24$ & - & 69.1 & 52.0 \\
\hline Daily smoker & 14.4 & $6.42 \pm 2.10$ & - & 76.9 & 65.3 \\
\hline Former smoker/experimenter & 7.7 & $5.59 \pm 2.29$ & - & 65.7 & 63.7 \\
\hline \multicolumn{6}{|l|}{ Smoking parents } \\
\hline No smoking parents & 60.1 & $4.72 \pm 2.43$ & 12.7 & 55.6 & 47.6 \\
\hline 1 smoking parent & 25.8 & $5.48 \pm 2.36$ & 24.4 & 62.6 & 60.2 \\
\hline$\geq 2$ smoking (step)parents & 14.1 & $5.90 \pm 2.20$ & 33.9 & 69.4 & 70.2 \\
\hline \multicolumn{6}{|l|}{ Smoking friends } \\
\hline None of them & 30.7 & $3.67 \pm 2.22$ & 1.3 & 51.2 & 42.9 \\
\hline Some of them & 45.6 & $5.12 \pm 2.20$ & 11.7 & 59.6 & 55.1 \\
\hline Most of them & 20.3 & $6.63 \pm 1.95$ & 47.8 & 67.3 & 64.0 \\
\hline All of them & 3.3 & $7.41 \pm 1.86$ & 70.3 & 74.1 & 68.8 \\
\hline
\end{tabular}

a Percentage of students who are weekly smokers within subgroups.

b Percentage of students with low academic achievement within subgroups.

c Percentage of students with low parental educational level within subgroups.

with low and high academic achievement and parental educational level. Perceived smoking prevalence substantially varied at the school and country-level. Variance at the school-level was larger and variance at the country-level was smaller in students with low academic achievement and low parental educational level, as compared to their counterparts.

\subsection{Evaluation of potential limitations}

The perceived smoking prevalence score was measured on a 0 to 10 scale, with 10 corresponding to a smoking prevalence of $100 \%$ among same-aged students at the same school. The scale has, to our knowledge, not been validated. Validity may be reduced in three ways. First, the concept of percentages might have been difficult for students, and they might have scored the perceived importance of smoking in their

Table 2

School-level characteristics of the SILNE 2013 study population, stratified by country.

\begin{tabular}{|c|c|c|c|c|c|c|c|}
\hline & General population & Namur (BE) & Tampere (FI) & Hannover (DE) & Latina (IT) & Amersfoort (NL) & Coimbra (PT) \\
\hline $\mathrm{N}$ schools & 50 & 7 & 8 & 13 & 8 & 8 & 6 \\
\hline $\mathrm{N}$ staff respondents & 276 & 88 & 32 & 67 & 36 & 28 & 25 \\
\hline $\mathrm{N}$ student respondents (response rate in \%) & $10,283(79.4)$ & 1935 (89.8) & $1456(86.0)$ & $1322(66.0)$ & $2008(76.5)$ & 1837 (80.9) & $1725(78.9)$ \\
\hline Perceived smoking prevalence score $(\text { mean } \pm S D)^{a}$ & $4.95 \pm 1.60$ & $5.84 \pm 0.89$ & $3.71 \pm 0.68$ & $4.57 \pm 1.59$ & $6.97 \pm 0.84$ & $3.59 \pm 1.24$ & $5.54 \pm 0.77$ \\
\hline Actual weekly smoking prevalence $(\% \text { smokers } \pm S D)^{\mathrm{b}}$ & $22.20 \pm 11.73$ & $25.47 \pm 7.11$ & $19.59 \pm 11.45$ & $19.80 \pm 13.16$ & $33.74 \pm 12.73$ & $15.85 \pm 8.62$ & $20.10 \pm 5.91$ \\
\hline Cigarettes available $<100 \mathrm{~m}$ (\% yes) & 56.0 & 85.7 & 50.0 & 46.2 & 62.5 & 37.5 & 66.7 \\
\hline Policy staff reported $(\text { mean } \pm S D)^{c}$ & $5.84 \pm 0.82$ & $5.78 \pm 0.47$ & $6.41 \pm 0.76$ & $5.76 \pm 0.60$ & $5.12 \pm 0.70$ & $5.65 \pm 1.10$ & $6.53 \pm 0.57$ \\
\hline
\end{tabular}

Means of school-level aggregated perceived smoking prevalence scores on a 0 to 10 scale. High scores indicate high perceived prevalence rates.

b Mean school-level weekly smoking prevalence rates, weighted by age.

c Staff reported anti-smoking policy of the school on a 0 to 10 scale. High scores indicate stronger anti-smoking policy. 


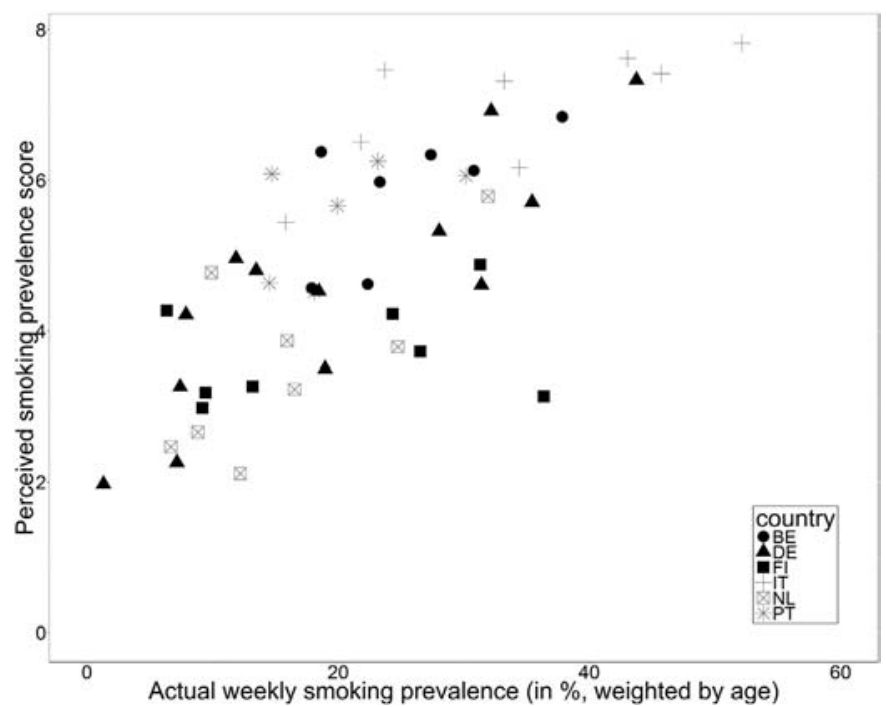

Fig. 1. Plot of school means of the actual weekly smoking prevalence (in \%, weighted by age) and the perceived smoking prevalence score (on a 0-10 scale), presented by country (SILNE 2013 data).

school rather than the percentage of smokers. Second, students may have 'escaped the extremes', leading to answers around the middle of the scale (50\%). Third, the use of a discrete scale prompted students to choose between steps of $10 \%$ on the scale, instead of estimating precise smoking rates. For these reasons, the perceived prevalence score derived from this scale could not be used as precise estimates of smoking prevalence rates, and direct comparisons with actual prevalence rates should be made with caution. Therefore we cannot quantify the extent of overestimation of the smoking prevalence. However, we did not find reasons to assume that misinterpretation of the scale would systematically differ between subgroups of students and comparisons between groups therefore seem valid.

Twelve percent $(\mathrm{N}=1246)$ of students did not report their parents' educational level. These students were excluded in the stratified analysis. We found that the perceived prevalence score was 0.51 points lower $(95 \% \mathrm{CI}=-0.65 ;-0.36)$ in students with missing information. However, the prevalence of determinants of perceived smoking prevalence, including own smoking, was very similar in those with or without missing information on parental educational level.

This study was conducted in the school setting and asked specifically for the perception of the prevalence of smoking among adolescents in the same school. Most previous studies on perceived smoking prevalence have also used the school setting as a reference for smoking prevalence perceptions(Conley Thomson et al., 2005; Javier et al., 2013; Pedersen et al., 2013; Wiium et al., 2006). Despite the limitation to school settings, the results of this and other studies may be more widely applicable. Studies in other settings also found that the perception of smoking in the general population was associated with smoking initiation (Nichols et al., 2006), and a few of these studies identified the same determinants as observed in our study (Conley Thomson et al., 2005).

\subsection{Interpretation of results}

Few studies have investigated the determinants of perceived smoking prevalence (Brown et al., 2010; Conley Thomson et al., 2005; Javier et al., 2013; Pedersen et al., 2013; Unger and Rohrbach, 2002). Although these studies are all from the USA, their results are consistent with those found in our study. Smoking prevalence estimates were higher in older adolescents (Conley Thomson et al., 2005; Pedersen et al., 2013), females (Javier et al., 2013; Pedersen et al., 2013; Unger and Rohrbach, 2002), students of foreign background (Javier et al., 2013; Unger and Rohrbach, 2002), smokers (Conley Thomson et al.,
2005), students with smoking friends (Conley Thomson et al., 2005; Unger and Rohrbach, 2002), lower achieving students (Unger and Rohrbach, 2002), students of low educated parents (Conley Thomson et al., 2005), students who had no household smoking ban (Conley Thomson et al., 2005), and students in schools with a higher actual smoking prevalence (Unger and Rohrbach, 2002). However, there were also some conflicting results for foreign background (Conley Thomson et al., 2005; Pedersen et al., 2013; Unger and Rohrbach, 2002), and gender (Conley Thomson et al., 2005).

Perceiving very high rates of peer smoking may be due to psychological mechanisms. According to the false consensus effect, individuals tend to overestimate the prevalence of behaviour when they perceive this behaviour as being normal or desired (Sherman et al., 1983). If so, perceived prevalence might be higher because some groups of adolescents in Europe think smoking is a normal or even desired behaviour. According to the pluralistic ignorance mechanism, individuals would perceive their own beliefs and feelings to differ from others in a group, even when they all behave similarly (Miller and McFarland, 1991; O'Gorman, 1988). This would imply that even if there are few smokers in a school, non-smoking adolescents may still perceive smoking as a desired behaviour. Such perception may be due to a high visibility of a small group of smokers at the school premises or exposure to images of smoking in the general environment including media (Hines et al., 2002).

False consensus and pluralistic ignorance effects may be stronger in some subgroups than in others (Conley Thomson et al., 2005; Paul et al., 2010). However, to our knowledge, variations in these psychological mechanisms have not been documented in the literature (Mullen et al., 1985). There may be other reasons for variation in smoking estimates between subgroups. Possibly, higher perceived smoking rates reflect higher actual prevalence rates within the same subgroup, instead of the prevalence in the whole school. For example, in our sample, smoking by students was more common in older adolescents, students with lower academic achievement, and students of parents with lower educational level. However, when comparing subgroups of students, Unger and colleagues (Unger and Rohrbach, 2002) found no association between the actual smoking prevalence within the subgroup and the perceived smoking prevalence.

Both measures of education, academic achievement of the adolescent and parental educational level of the parents, showed very similar results. Students in low educational groups may perceive higher smoking rates for several reasons. First, estimating a higher smoking prevalence is associated with perceiving smoking as less risky (Brown et al., 2010). Previous studies found that individuals of low education had lower perceived risk of smoking (Lee et al., 2008; Peretti-Watel et al., 2014; Siahpush et al., 2006). Second, smoking prevalence estimates are positively associated with perceived ease of access to cigarettes and with cigarettes being offered by friends (Unger and Rohrbach, 2002). Perceived access and cigarette offers may differ between groups of education. Third, perceived smoking may be influenced by exposure to smoking outside the school context, for example in social/sports clubs, the neighbourhood, via internet (including social media), or in television and movies (Charlesworth and Glantz, 2005; Kuipers et al., 2013; Strasburger et al., 2010; Unger and Rohrbach, 2002). The exposure to such images may be relatively high among students of low education groups. As these three factors may increase the extent to which smoking is viewed as a normal behaviour, they may reinforce pluralistic ignorance (Miller and McFarland, 1991; O'Gorman, 1988) and false consensus (Sherman et al., 1983) effects in lower education groups.

We observed cross-national variations in the perceived smoking prevalence score. To our knowledge, such variations have not been reported in previous studies. We were unable to study which factors at the country-level contributed to these variations, due to the limited number of countries. However, in theory, perceived smoking prevalence rates may be higher in countries where the smoking prevalence in 
Table 3

Perceived peer smoking prevalence score (on a 0-10 scale) by individual and school-level factors in six multilevel linear regression models (SILNE 2013 data).

\begin{tabular}{|c|c|c|c|c|c|c|c|}
\hline & \multicolumn{7}{|c|}{ Regression coefficient $(\beta)$ with 95\% confidence interval } \\
\hline & Model 0 & Model 1 & Model 2 & Model 3 & Model 4 & Model 5 & Model 6 \\
\hline \multicolumn{8}{|l|}{ Fixed effects } \\
\hline Intercept & $5.02[3.88 ; 6.17]$ & $5.02[4.22 ; 5.82]$ & $4.35[3.66 ; 5.05]$ & $4.26[2.14 ; 6.43]$ & $4.56[3.79 ; 5.33]$ & $5.56[4.78 ; 6.34]$ & $4.29[5.57 ; 6.06]$ \\
\hline Actual weekly smoking prevalence & & $0.75[0.53 ; 0.99]$ & $0.61[0.42 ; 0.83]$ & $0.69[0.47 ; 0.94]$ & $0.66[0.46 ; 0.89]$ & $0.68[0.48 ; 0.90]$ & $0.53[0.35 ; 0.73]$ \\
\hline \multicolumn{8}{|l|}{ Smoking friends } \\
\hline None of them & & & Ref & & & & Ref \\
\hline Some of them & & & $0.59[0.51 ; 0.68]$ & & & & $0.47[0.39 ; 0.56]$ \\
\hline Most of them & & & $1.50[1.39 ; 1.61]$ & & & & $1.24[1.12 ; 1.36]$ \\
\hline All of them & & & $2.14[1.93 ; 2.34]$ & & & & $1.79[1.57 ; 2.00]$ \\
\hline Cigarettes available $100 \mathrm{~m}$ & & & & $0.49[0.01 ; 0.99]$ & & & $0.37[-0.02 ; 0.76]$ \\
\hline School smoking policy & & & & $0.08[-0.26 ; 0.41]$ & & & $0.05[-0.23 ; 0.31]$ \\
\hline \multicolumn{8}{|l|}{ Smoking respondent } \\
\hline Never-smoker & & & & & Ref & & Ref \\
\hline Tried smoking & & & & & $0.49[0.36 ; 0.61]$ & & $0.27[0.15 ; 0.38]$ \\
\hline Experimenter & & & & & $0.57[0.47 ; 0.68]$ & & $0.20[0.09 ; 0.31]$ \\
\hline Regular smoker & & & & & $0.76[0.58 ; 0.93]$ & & $0.19[0.01 ; 0.36]$ \\
\hline Daily smoker & & & & & $0.94[0.83 ; 1.06]$ & & $0.14[0.02 ; 0.27]$ \\
\hline Former smoker or experimenter & & & & & $0.55[0.41 ; 0.68]$ & & $0.30[0.17 ; 0.44]$ \\
\hline \multicolumn{8}{|l|}{ Smoking parents } \\
\hline No smoking parents & & & & & Ref & & Ref \\
\hline 1 smoking parent & & & & & $0.12[0.03 ; 0.21]$ & & $0.07[-0.01 ; 0.16]$ \\
\hline$\geq 2$ smoking (step)parents & & & & & $0.19[0.07 ; 0.31]$ & & $0.10[-0.01 ; 0.21]$ \\
\hline \multicolumn{8}{|l|}{ Smoking rules at home } \\
\hline No where & & & & & Ref & & Ref \\
\hline Certain areas & & & & & $0.09[0.00 ; 0.18]$ & & $0.03[-0.06 ; 0.11]$ \\
\hline Everywhere & & & & & $0.31[0.15 ; 0.47]$ & & $0.22[0.07 ; 0.37]$ \\
\hline Age & & & & & & $0.28[0.24 ; 0.33]$ & $0.19[0.14 ; 0.23]$ \\
\hline Male gender & & & & & & -0.70 & -0.70 \\
\hline & & & & & & {$[-0.77 ;-0.63]$} & {$[-0.77 ;-0.63]$} \\
\hline Foreign background & & & & & & $0.12[0.04 ; 0.21]$ & $0.14[0.05 ; 0.22]$ \\
\hline \multicolumn{8}{|l|}{ Academic achievement } \\
\hline Insufficient or low & & & & & & Ref & Ref \\
\hline Average & & & & & & $\begin{array}{l}-0.34 \\
{[-0.45 ;-0.24]}\end{array}$ & $\begin{array}{l}-0.19 \\
{[-0.29 ;-0.09]}\end{array}$ \\
\hline Good & & & & & & -0.63 & -0.39 \\
\hline & & & & & & {$[-0.74 ;-0.52]$} & {$[-0.50 ;-0.29]$} \\
\hline High & & & & & & -0.85 & -0.49 \\
\hline & & & & & & {$[-1.00 ;-0.70]$} & {$[-0.63 ;-0.34]$} \\
\hline \multicolumn{8}{|l|}{ Education parents } \\
\hline Low & & & & & & Ref & Ref \\
\hline Middle & & & & & & -0.12 & -0.13 \\
\hline & & & & & & {$[-0.24 ;-0.01]$} & {$[-0.24 ;-0.01]$} \\
\hline High & & & & & & -0.28 & -0.25 \\
\hline & & & & & & {$[-0.40 ;-0.16]$} & {$[-0.36 ;-0.13]$} \\
\hline \multicolumn{8}{|l|}{ Random effects } \\
\hline \multicolumn{8}{|l|}{ School-level } \\
\hline Variance & 1.25 & 0.66 & 0.52 & 0.64 & 0.55 & 0.41 & 0.35 \\
\hline ICC (\%) & 20.23 & 13.84 & 13.50 & 13.50 & 12.33 & 10.68 & 9.62 \\
\hline \multicolumn{8}{|l|}{ Country-level } \\
\hline Variance & 1.59 & 0.77 & 0.57 & 0.76 & 0.72 & 0.55 & 0.41 \\
\hline ICC (\%) & 25.73 & 16.14 & 13.73 & 16.03 & 16.14 & 14.32 & 11.26 \\
\hline Residual variance & 3.34 & 3.34 & 3.06 & 3.34 & 3.19 & 2.88 & 2.88 \\
\hline Total variance & 6.18 & 4.77 & 4.15 & 4.74 & 4.46 & 3.84 & 3.64 \\
\hline
\end{tabular}

adults is high (Kuipers et al., 2015b) or where national and regional tobacco control policies are weak (Brown et al., 2015; Kuipers et al., 2015b). In our sample, countries with higher smoking prevalence estimates tended to have lower scores on the Tobacco Control Scale (TCS) in 2013 (e.g. Italy and Belgium). However, Germany had the lowest TCS score of the six countries, but not the highest perceived prevalence score (Joossens and Raw, 2014).

We found that cross-national variations were large in students with high academic achievement and high parental educational level. This suggests that country-level factors are more likely to influence smoking perception in high education groups than in low education groups. This finding bears resemblance to the findings of other studies which suggest that national level campaigns and policies may have stronger effects among high SEP adolescents than among their low SEP counterparts (Helakorpi et al., 2008; Kuipers et al., 2014; White et al., 2008). There is some evidence that anti-smoking mass media campaigns can influence social norm perceptions of smoking among young people (Brown and Moodie, 2009; Gunther et al., 2006).

We observed a substantial variation between schools in perceived smoking prevalence, but we found no association with specific schoolrelated factors such as school smoking policies and cigarette availability near the school. Such factors may however have indirect effects through their potential effect on the actual smoking prevalence in the school (Galanti et al., 2013). The combined direct and indirect effects of school-related determinants were assessed in a post hoc analysis, by excluding the actual smoking prevalence from Model 6 of Table 3. We found that the availability of cigarettes near the school, but not school smoking policies, was significantly associated with higher perceived prevalence scores.

The fact that between-school variations were relatively large in students of lower educational groups corresponds to evidence suggesting larger effects of school-level smoking policies (Kuipers et al., 2015a) and the British school-based intervention ASSIST (Brown et al., 2015) 


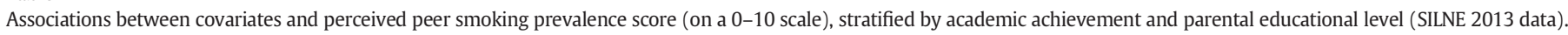

\begin{tabular}{|c|c|c|c|c|c|c|}
\hline & \multicolumn{6}{|c|}{ Regression coefficient ( $\beta$ ) with 95\% confidence intervala } \\
\hline & $\begin{array}{l}\text { Low academic } \\
\text { achievement }\end{array}$ & $\begin{array}{l}\text { High academic } \\
\text { achievement }\end{array}$ & $\begin{array}{l}p \text {-Value } \\
\text { interaction }^{\mathrm{b}}\end{array}$ & $\begin{array}{l}\text { Low parental } \\
\text { education }\end{array}$ & $\begin{array}{l}\text { High parental } \\
\text { education }\end{array}$ & $\begin{array}{l}p \text {-Value } \\
\text { interaction }^{\mathrm{b}}\end{array}$ \\
\hline \multicolumn{7}{|l|}{ Fixed effects } \\
\hline Actual smoking prevalence & $0.51[0.33 ; 0.69]$ & $0.58[0.39 ; 0.77]$ & 0.049 & $0.53[0.35 ; 0.72]$ & $0.60[0.41 ; 0.79]$ & 0.105 \\
\hline \multicolumn{7}{|l|}{ Smoking friends } \\
\hline None of them & Ref & Ref & & Ref & Ref & \\
\hline Some of them & $0.49[0.38 ; 0.61]$ & $0.46[0.34 ; 0.59]$ & 0.717 & $0.42[0.29 ; 0.54]$ & $0.48[0.36 ; 0.61]$ & 0.428 \\
\hline Most of them & $1.13[0.98 ; 1.27]$ & $1.49[1.32 ; 1.66]$ & $<0.001$ & $1.13[0.97 ; 1.28]$ & $1.36[1.19 ; 1.54]$ & 0.026 \\
\hline All of them & $1.67[1.42 ; 1.92]$ & $2.07[1.68 ; 2.45]$ & 0.074 & $1.61[1.34 ; 1.88]$ & $1.96[1.59 ; 2.33]$ & 0.115 \\
\hline Cigarettes available 100 m & $0.41[0.02 ; 0.80]$ & $0.32[-0.08 ; 0.71]$ & 0.201 & $0.38[-0.02 ; 0.77]$ & $0.34[-0.06 ; 0.74]$ & 0.644 \\
\hline Policy staff reported & $0.09[-0.18 ; 0.35]$ & $-0.03[-0.30 ; 0.23]$ & 0.008 & $0.01[-0.26 ; 0.29]$ & $-0.03[-0.30 ; 0.25]$ & 0.412 \\
\hline \multicolumn{7}{|l|}{ Smoking respondent } \\
\hline Never-smoker & Ref & Ref & & Ref & Ref & \\
\hline Tried smoking & $0.14[-0.02 ; 0.29]$ & $0.43[0.24 ; 0.61]$ & 0.018 & $0.33[0.16 ; 0.50]$ & $0.21[0.03 ; 0.40]$ & 0.345 \\
\hline Experimenter & $0.20[0.06 ; 0.33]$ & $0.20[0.02 ; 0.38]$ & 0.994 & $0.12[-0.03 ; 0.28]$ & $0.33[0.17 ; 0.49]$ & 0.060 \\
\hline Regular smoker & $0.08[-0.13 ; 0.29]$ & $0.43[0.13 ; 0.74]$ & 0.055 & $0.15[-0.10 ; 0.39]$ & $0.19[-0.06 ; 0.45]$ & 0.795 \\
\hline Daily smoker & $0.05[-0.09 ; 0.19]$ & $0.35[0.14 ; 0.56]$ & 0.010 & $0.14[-0.01 ; 0.29]$ & $0.09[-0.10 ; 0.28]$ & 0.656 \\
\hline Former smoker & $0.32[0.15 ; 0.48]$ & $0.29[0.07 ; 0.51]$ & 0.842 & $0.27[0.10 ; 0.44]$ & $0.42[0.20 ; 0.64]$ & 0.289 \\
\hline \multicolumn{7}{|l|}{ Smoking parents } \\
\hline No smoking parents & Ref & Ref & & Ref & Ref & \\
\hline 1 smoking parent & $0.05[-0.06 ; 0.16]$ & $0.15[0.02 ; 0.28]$ & 0.232 & $-0.01[-0.12 ; 0.11]$ & $0.12[-0.01 ; 0.25]$ & 0.122 \\
\hline$\geq 2$ smoking (step)parents & $0.05[-0.08 ; 0.18]$ & $0.20[0.02 ; 0.38]$ & 0.164 & $-0.01[-0.15 ; 0.13]$ & $0.17[-0.01 ; 0.36]$ & 0.100 \\
\hline \multicolumn{7}{|l|}{ Smoking rules at home } \\
\hline No where & Ref & Ref & & Ref & Ref & \\
\hline Certain areas & $-0.07[-0.18 ; 0.04]$ & $0.12[-0.00 ; 0.25]$ & 0.017 & $-0.03[-0.15 ; 0.08]$ & $0.08[-0.05 ; 0.21]$ & 0.187 \\
\hline Everywhere & $0.22[0.04 ; 0.40]$ & $0.16[-0.10 ; 0.41]$ & 0.682 & $0.17[-0.03 ; 0.36]$ & $0.30[0.03 ; 0.57]$ & 0.412 \\
\hline Age & $0.18[0.12 ; 0.23]$ & $0.23[0.16 ; 0.29]$ & 0.216 & $0.17[0.12 ; 0.23]$ & $0.20[0.14 ; 0.27]$ & 0.409 \\
\hline Male gender & $-0.72[-0.80 ;-0.63]$ & $-0.73[-0.84 ;-0.62]$ & 0.808 & $-0.69[-0.79 ;-0.59]$ & $-0.81[-0.91 ;-0.70]$ & 0.109 \\
\hline Foreign background & $0.18[0.07 ; 0.29]$ & $0.14[0.01 ; 0.28]$ & 0.714 & $0.13[0.01 ; 0.25]$ & $0.24[0.11 ; 0.37]$ & 0.213 \\
\hline \multicolumn{7}{|l|}{ Academic achievement } \\
\hline Insufficient or low & - & - & - & Ref & Ref & \\
\hline Average & - & - & - & $-0.30[-0.43 ;-0.17]$ & $-0.07[-0.24 ; 0.10]$ & 0.031 \\
\hline Good & - & - & - & $-0.42[-0.57 ;-0.28]$ & $-0.30[-0.47 ;-0.13]$ & 0.267 \\
\hline High & - & - & - & $-0.39[-0.61 ;-0.17]$ & $-0.48[-0.68 ;-0.27]$ & 0.567 \\
\hline \multicolumn{7}{|l|}{ Education parents } \\
\hline Low & Ref & Ref & & - & - & - \\
\hline Middle & $-0.14[-0.28 ; 0.00]$ & $-0.08[-0.27 ; 0.12]$ & 0.622 & - & - & - \\
\hline High & $-0.23[-0.37 ;-0.08]$ & $-0.28[-0.47 ;-0.09]$ & 0.663 & - & - & - \\
\hline \multicolumn{7}{|l|}{ Random effects } \\
\hline \multicolumn{7}{|l|}{ School-level } \\
\hline Variance & 0.43 & 0.32 & & 0.49 & 0.30 & \\
\hline ICC (\%) & 11.47 & 7.98 & & 12.95 & 7.92 & \\
\hline \multicolumn{7}{|l|}{ Country-level } \\
\hline Variance & 0.45 & 0.89 & & 0.58 & 0.73 & \\
\hline ICC (\%) & 12.00 & 22.19 & & 14.95 & 19.26 & \\
\hline Residual variance & 2.87 & 2.80 & & 2.81 & 2.76 & \\
\hline Total variance & 3.75 & 4.01 & & 3.88 & 3.79 & \\
\hline
\end{tabular}

a All regression coefficients are controlled for the variables included in the table.

b $p$-Values indicate the level of significance of interaction tests between academic achievement or parental educational level and the covariates presented in the table.

on low SEP adolescents' smoking. The large variation found at the school-level suggests that the school is a suitable setting for interventions aimed at altering false perceptions among adolescents, especially for low SEP adolescents. However, the perceived smoking was not significantly associated with the included school-level factors (i.e. school smoking policies and the access to tobacco in the school surroundings). Characteristics of the school that might be more relevant include school type (e.g. the educational tracks in a school) (Moore et al., 2001), smoking prevalence among teachers, and the visibility of smoking near the school. There is evidence to claim that interventions aimed to enhance social competences and social influences are more effective in preventing the onset of smoking, than interventions aimed to transmit factual information (Thomas et al., 2013). Possibly, the former interventions may also be more effective in altering students' perceptions of the school-level smoking prevalence.

\section{Conclusions}

Perceived peer smoking scores were lower in males, in nonsmokers, in students with non-smoking friends. This was true for adolescents with both high and low levels of academic achievement and parental educational level. Perceived smoking varied considerably between schools and between countries. This suggests that there is an important role for policies at both national and school levels to influence the perceived smoking prevalence, but the effectiveness of different strategies remains a topic for further studies.

Supplementary data to this article can be found online at http://dx. doi.org/10.1016/j.ypmed.2016.04.016.

\section{Conflict of interest statement}

The authors declare that there are no conflicts of interest.

\section{Acknowledgements}

The authors would like to acknowledge their colleagues involved in the collection of the SILNE data: Jaana Kinnunen, Geatano Roscillo, Irene Moor, and Joana Alves.

This study is part of the project 'Tackling socio-economic inequalities in smoking (SILNE)', which is funded by the European Commission, Directorate-General for Research and Innovation, under the FP7- 
Health-2011 programme, with grant agreement number 278273. The funder was not involved in any part of this study, including the study design; the collection, analysis, and interpretation of data; the writing of the report; and the decision to submit the article for publication.

\section{References}

Alexander, C., Piazza, M., Mekos, D., Valente, T., 2001. Peers, schools, and adolescent cigarette smoking. J. Adolesc. Health 29, 22-30.

Bandura, A., McClelland, D.C., 1977. Social Learning Theory. Prentice-Hall, Englewood Cliffs, NJ.

Brown, A., Moodie, C., 2009. The influence of tobacco marketing on adolescent smoking intentions via normative beliefs. Health Educ. Res. 24, 721-733.

Brown, A.K., Moodie, C., Hastings, G., Mackintosh, A.-M., Hassan, L., Thrasher, J., 2010. The association of normative perceptions with adolescent smoking intentions. J. Adolesc. 33, 603-614.

Brown, T., Platt, S., Amos, A., 2015. Equity impact of interventions and policies to reduce smoking in youth: systematic review. Tob. Control. 23, 98-105.

Charlesworth, A., Glantz, S.A., 2005. Smoking in the movies increases adolescent smoking: a review. Pediatrics 116, 1516-1528.

Conley Thomson, C., Siegel, M., Winickoff, J., Biener, L., Rigotti, N.A., 2005. Household smoking bans and adolescents' perceived prevalence of smoking and social acceptability of smoking. Prev. Med. 41, 349-356.

de Looze, M., Ter Bogt, T., Hublet, A., Kuntsche, E., Richter, M., Zsiros, E., Godeau, E., Vollebergh, W., 2013. Trends in Educational Differences in Adolescent Daily Smoking across Europe, 2002-10. Eur. J. Pub. Health.

Doku, D., Koivusilta, L., Rainio, S., Rimpelä, A., 2010. Socioeconomic differences in smoking among Finnish adolescents from 1977 to 2007. J. Adolesc. Health 47, 479-487.

Edwards, C.L., Bennett, G.G., Wolin, K.Y., Johnson, S., Fowler, S., Whitfield, K.E., Askew, S., MacKinnon, D., McDougald, C., et al., 2008. Misestimation of peer tobacco use: understanding disparities in tobacco use. J. Natl. Med. Assoc. 100, 299-302.

Ellickson, P.L., Bird, C.E., Orlando, M., Klein, D.J., McCaffrey, D.F., 2003. Social context and adolescent health behavior: does school-level smoking prevalence affect students subsequent smoking behavior? J. Health Soc. Behav. 525-535.

Elsey, H., Owiredu, E., Thomson, H., Mann, G., Mehta, R., Siddiqi, K., 2015. Do children overestimate the extent of smoking among their peers? A feasibility study of the social norms approach to prevent smoking. Addict. Behav. 41, 7-11.

Galanti, M.R., Coppo, A., Jonsson, E., Bremberg, S., Faggiano, F., 2013. Anti-tobacco policy in schools: upcoming preventive strategy or prevention myth? A review of 31 studies. Tob Control: http://dx.doi.org/10.1136/tobaccocontrol-2012-050846.

Gunther, A.C., Bolt, D., Borzekowski, D.L., Liebhart, J.L., Dillard, J.P., 2006. Presumed influence on peer norms: how mass media indirectly affect adolescent smoking. J. Commun. 56, 52-68.

Helakorpi, S., Martelin, T., Torppa, J., Vartiainen, E., Uutela, A., Patja, K., 2008. Impact of the 1976 Tobacco Control Act in Finland on the proportion of ever daily smokers by socioeconomic status. Prev. Med. 46, 340-345.

Hibell, B., Guttormsson, U., Ahlström, S., Balakireva, O., Bjarnason, T., Kokkevi, A., Kraus, L. 2012. Substance use among students in 36 EUROPEAN countries. The Swedish Council for Information on Alcohol and Other Drugs (CAN), Stockholm. The 2011 ESPAD Report.

Hines, D., Saris, R.N., Throckmorton-Belzer, L., 2002. Pluralistic ignorance and health risk behaviors: do college students misperceive social approval for risky behaviors on campus and in media? J. Appl. Soc. Psychol. 32, 2621-2640.

Hiscock, R., Bauld, L., Amos, A., Fidler, J.A., Munafo, M., 2012. Socioeconomic status and smoking: a review. Ann. N. Y. Acad. Sci. 1248, 107-123.

Hoffman, B.R., Sussman, S., Unger, J.B., Valente, T.W., 2006. Peer influences on adolescent cigarette smoking: a theoretical review of the literature. Subst. Use Misuse 41 103-155.

Javier, S.J., Belgrave, F.Z., Hill, K.E.V., Richardson, J.T., 2013. Ethnic and gender differences in normative perceptions of substance use and actual use among college students. J. Ethin. Subst. Abus. 12, 228-241.

Joossens, L., Raw, M., 2014. The Tob Control Scale 2013 in Europe.

Kobus, K., 2003. Peers and adolescent smoking. Addiction 98, 37-55.

Kuipers, M.A., De Korte, R., Soto, V.E., Richter, M., Moor, I., Rimpelä, A.H., Perelman, J., Federico, B., Kunst, A.E., et al., 2015a. School smoking policies and educational inequalities in smoking behaviour of 14 to 17 -year-old adolescents in Europe. J. Epidemiol. Community Health 70 (2), 132-139.

Kuipers, M.A., Monshouwer, K., Van Laar, M., Kunst, A.E., 2015b. Tobacco control and socioeconomic inequalities in adolescent smoking in Europe. Am. J. Prev. Med. 49 (5), e64-e72.

Kuipers, M.A., Nagelhout, G.E., Willemsen, M.C., Kunst, A.E., 2014. Widening educational inequalities in adolescent smoking following national tobacco control policies in the Netherlands in 2003: a time series analysis. Addiction 109 (10), 1750-1759.

Kuipers, M.A., Wingen, M., Stronks, K., Kunst, A.E., 2013. Smoking initiation, continuation and prevalence in deprived urban areas compared to non-deprived urban areas in The Netherlands. Soc. Sci. Med. 87, 132-137.

Lai, M.K., Ho, S.Y., Lam, T.H., 2004. Perceived peer smoking prevalence and its association with smoking behaviours and intentions in Hong Kong Chinese adolescents. Addiction 99, 1195-1205.

Lapinski, M.K., Rimal, R.N., 2005. An explication of social norms. Commun. Theor 15 127-147.

Lee, J.E., Lemyre, L., Turner, M.C., Orpana, H.M., Krewski, D., 2008. Health risk perceptions as mediators of socioeconomic differentials in health behaviour. J. Health Psychol. 13, 1082-1091.
Lifestyle statistics team, 2014. Statistics on Smoking: England 2014. Health and Social Care Information Centre, Leeds.

Lorant, V., Soto, V.E., Moor, I., Richter, M., Robert, P.O., Kinnunen, J., Rimpelä, A., Kuipers, M.A., Roscillo, G., et al., 2015. Smoking in school-aged adolescents: design and validation of a social network survey in six European cities. BMC Res Notes.

Merlo, J., Chaix, B., Ohlsson, H., Beckman, A., Johnell, K., Hjerpe, P., Råstam, L., Larsen, K., 2006. A brief conceptual tutorial of multilevel analysis in social epidemiology: using measures of clustering in multilevel logistic regression to investigate contextual phenomena. J. Epidemiol. Community Health 60, 290-297.

Miller, D.T., McFarland, C., 1991. When Social Comparison Goes awry: The Case of Pluralistic Ignorance. Erlbaum, Hillsdale, NJ.

Moore, L., Roberts, C., Tudor-Smith, C., 2001. School smoking policies and smoking prevalence among adolescents: multilevel analysis of cross-sectional data from Wales. Tob. Control. 10, 117-123.

Mullen, B., Atkins, J.L., Champion, D.S., Edwards, C., Hardy, D., Story, J.E., Vanderklok, M., 1985. The false consensus effect: a meta-analysis of 115 hypothesis tests. J. Exp. Soc. Psychol. 21, 262-283.

Nichols, T.R., Birnbaum, A.S., Birnel, S., Botvin, G.J., 2006. Perceived smoking environment and smoking initiation among multi-ethnic urban girls. J. Adolesc. Health 38, 369-375.

O'Gorman, H.J., 1988. Pluralistic ignorance and reference groups: the case of ingroup ignorance. Surveying Social Life, pp. 145-173 Papers in honor of Herbert H. Hyman.

Otten, R., Engels, R.C., Prinstein, M.J., 2009. A prospective study of perception in adolescent smoking. J. Adolesc. Health 44, 478-484

Paul, C.L., Ross, S., Bryant, J., Hill, W., Bonevski, B., Keevy, N., 2010. The social context of smoking: a qualitative study comparing smokers of high versus low socioeconomic position. BMC Pub. Health 10, 211

Pedersen, E.R., Miles, J.N., Ewing, B.A., Shih, R.A., Tucker, J.S., D'Amico, E.J., 2013. A longitudinal examination of alcohol, marijuana, and cigarette perceived norms among middle school adolescents. Drug Alcohol Depend. 133, 647-653.

Peretti-Watel, P., Seror, V., Verger, P., Guignard, R., Legleye, S., Beck, F., 2014. Smokers' risk perception, socioeconomic status and source of information on cancer. Addict. Behav. 39, 1304-1310.

Pförtner, T.K., Moor, I., Rathmann, K., Hublet, A., Molcho, M., Kunst, A.E., Richter, M., 2014. The association between family affluence and smoking among 15-year-old adolescents in 33 European countries, Israel and Canada: the role of national wealth. Addiction.

Richter, M., Leppin, A., 2007. Trends in socio-economic differences in tobacco smoking among German schoolchildren, 1994-2002. Eur. J. Pub. Health 17, 565-571.

Sherman, S.J., Presson, C.C., Chassin, L., Corty, E., Olshavsky, R., 1983. The false consensus effect in estimates of smoking prevalence underlying mechanisms. Pers. Soc. Psychol. Bull. 9, 197-207.

Siahpush, M., McNeill, A., Hammond, D., Fong, G., 2006. Socioeconomic and country variations in knowledge of health risks of tobacco smoking and toxic constituents of smoke: results from the 2002 International Tobacco Control (ITC) Four Country Survey. Tob Control 15:iii65-iii70.

Strasburger, V.C., Jordan, A.B., Donnerstein, E., 2010. Health effects of media on children and adolescents. Pediatrics 125, 756-767.

Thomas, R.E., McLellan, J., Perera, R., 2013. School-based programmes for preventing smoking. Evidence-Based Child Health: A Cochrane Review Journal 8, 1616-2040.

Thrul, J., Lipperman-Kreda, S., Grube, J.W., Friend, K.B., 2013. Community-level adult daily smoking prevalence moderates the association between adolescents' cigarette smoking and perceived smoking by friends. J. Youth Adolesc. 1-9.

Unger, J.B., Rohrbach, L.A., 2002. Why do adolescents overestimate their peers' smoking prevalence? Correlates of prevalence estimates among California 8th-grade students. J. Youth Adolesc. 31, 147-153.

US Department of Health Human Services, 2012. Preventing Tobacco Use among Youth and Young Adults: a Report of the Surgeon General, Atlanta, GA: US Department of Health and Human Services, Centers for Disease Control and Prevention, National Center for Chronic Disease Prevention and Health Promotion, Office on Smoking and Health. US Department of Health and Human Services, Public Health Service, Office of the Surgeon General, Rockville, MD.

US Department of Health Human Services, 2014. The health consequences of smoking-50 years of progress: a report of the Surgeon General U.S. Department of Health and Human Services, Centers for Disease Control and Prevention, National Center for Chronic Disease Prevention and Health Promotion, Office on Smoking and Health, Atlanta, GA

Wang, M.P., Ho, S.Y., Lo, W.S., Lam, T.H., 2011. Overestimation of peer smoking prevalence predicts smoking initiation among primary school students in Hong Kong. J. Adolesc. Health 48, 418-420.

White, V.M., Hayman, J., Hill, D.J., 2008. Can population-based tobacco-control policies change smoking behaviors of adolescents from all socio-economic groups? Findings from Australia: 1987-2005. Cancer Causes Control 19, 631-640.

Wiium, N., Torsheim, T., Wold, B., 2006. Normative processes and adolescents' smoking behaviour in Norway: a multilevel analysis. Soc. Sci. Med. 62, 1810-1818.

Yaman, A., Mesman, J., van IJzendoorn, M.H., Bakermans-Kranenburg, M.J., Linting, M., 2010. Parenting in an individualistic culture with a collectivistic cultural background: the case of Turkish immigrant families with toddlers in The Netherlands. J. Child Fam. Stud. 19, 617-628.

Zaleski, A.C., Aloise-Young, P.A., 2013. Using peer injunctive norms to predict early adolescent cigarette smoking intentions. J. Appl. Soc. Psychol. 43, E124-E31.

Zehe, J.M., Colder, C.R., Read, J.P., Wieczorek, W.F., Lengua, L.J., 2013. Social and generalized anxiety symptoms and alcohol and cigarette use in early adolescence: the moderating role of perceived peer norms. Addict. Behav. 38, 1931-1939. 